\title{
XXXVII. On the relation between the density and composition of dilute sulphuric acid
}

\section{A. W. Rücker F.R.S.}

To cite this article: A. W. Rücker F.R.S. (1891) XXXVII. On the relation between the density and composition of dilute sulphuric acid , Philosophical Magazine Series 5, 32:196, 304-313, DOI: $10.1080 / 14786449108620185$

To link to this article: http://dx.doi.org/10.1080/14786449108620185

曲 Published online: 08 May 2009.

Submit your article to this journal $\sqsubset \pi$

Џ Article views: 2

Q View related articles $\widetilde{ }$ 
earth; and $\mathrm{G}$ (i.e. N) through a high-resistance galvanometer to earth, the indications of the galvanometer being therefore due only to current discharged from N. A much larger instrument constructed on the same lines was used for needle $A$ and other measurements. The body of this instrument is a tin cylinder 43 centim. long (horizontally) and 23 centim. in diameter. The needle is suspended in a small metal box at the centre, and the electrified plate is supported like CD (fig. 1) from one end.

The tilting is effected in each of the above instruments by fixing them to a brass base, provided with pivots at one end and a vertical micrometer-screw with large divided head at the other. This method works admirably.

In conclusion I wish to express my thanks to my friend Mr. F. B. Fawcett, a former student of University College, Bristol, and to my assistant Mr. J. Quick, for much careful help in carrying out the measurements described in this paper. To Prof. Lodge my thanks are so numerous that I cannot express them. His kindness, both by word and by deed, has been unceasing. Indeed but for him this paper would probably nover have been written.

University College, Bristol.

XXXVII. On the Relation between the Density and Composition of Dilute Sulphuric Acid. By A. W. RöckER, F.R.S.*

@OME time ago I had occasion to examine closely $\mathrm{Mr}$. $\$$ Pickering's method of detecting breaks in curves representing the results of experiments, and in consequence of the recent controversy on the subject I have lately reconsidered the matter.

Mr. Pickering's work covers a wide area, and he cannot complain if those who study his method devote themselves particularly to some one application of it.

I have specially investigated the curve which expresses between 46 per cent. and 80 per cent. the relation at $18^{\circ}$ between the percentage strength of the solution and the "first differential" of the densities.

This was chosen on two grounds. First, because it includes within its range the percentage corresponding to the hydrate which Mr. Pickering has isolated. Secondly, because, although Mr. Pickering estimates the magnitude of the possible error of observation to be greater at $18^{\circ}$ than at other temperatures, the agreement between his curves and

* Communicated by the Author. 
the results of observation appears in this case to be freer from exceptional, and possibly accidental, causes of disturbance than in others.

I have therefore tried to find an equation which will express a considerable portion of this curve to within the limits of the error of experiment.

If a curve, determined from isolated points, is discontinuous, it is nevertheless often possible-though perhaps difficult-to express it by a moderately simple continuous equation. To do this, however, terms would have to be introduced which express the rapid change of curvature in the neighbourhood of the point of discontinuity.

$\mathrm{My}$ equation, however, consists of three parts, which are not suited to turning awkward corners.

The lower part of the curve is nearly a straight line. The differences between the ordinates of the upper part of the curve and those of this line are very accurately in geometrical progression.

If this were all, the equation would be of the form

$$
y=a+b x-c d^{x} \text {. }
$$

As a matter of fact, for the middle region this curve lies a little below that given by experiment. The difference gradually increases, reaches a maximum, and dies out; but the change is very gradual, extends over a considerable range, and does not in the least suggest discontinuity.

To make the two curves, given by observation and calculation, fit, I have introduced a term which makes the form of the equation

$$
y=a+b x-c d^{x}+\frac{m}{n^{x}+n^{-x}} .
$$

A curve of this kind has in all seven arbitrary constants, for if we change the origin to $x_{0} y_{0}$ it may be written

where

$$
y=a^{\prime}+b x-c^{\prime} \cdot d^{x}+\frac{m k}{n^{x}+k^{2} n^{-x}}
$$

$$
k=n^{x_{0}} .
$$

In the following Table $I$ give the values of the three termse $a+b x, c d^{x}$, and $m /\left(n^{x}+n^{-x}\right)$, so that the fact that no term introduces violent and sudden changes may be obvious.

I have carried out the calculations to one place further than the results of the observations are given, as Mr. Pickering uses that place in the readings from his smoothed curve, given in Table III. of his paper (Trans. Chem. Soc., March 1890 , p. 145). 
The values of the constants are as follows when $x=p-61$ ( $p \equiv$ percentage) :-

$$
\begin{aligned}
a & =0 \cdot 010957, \\
l, & =0 \cdot 0001119, \\
c & =0 \cdot 00006458, \\
d & =1 \cdot 1925, \\
m & =0 \cdot 00011, \\
k & =1, \\
n & =\sqrt{ } 6=1 \cdot 348 .
\end{aligned}
$$

\section{TABLE 1.}

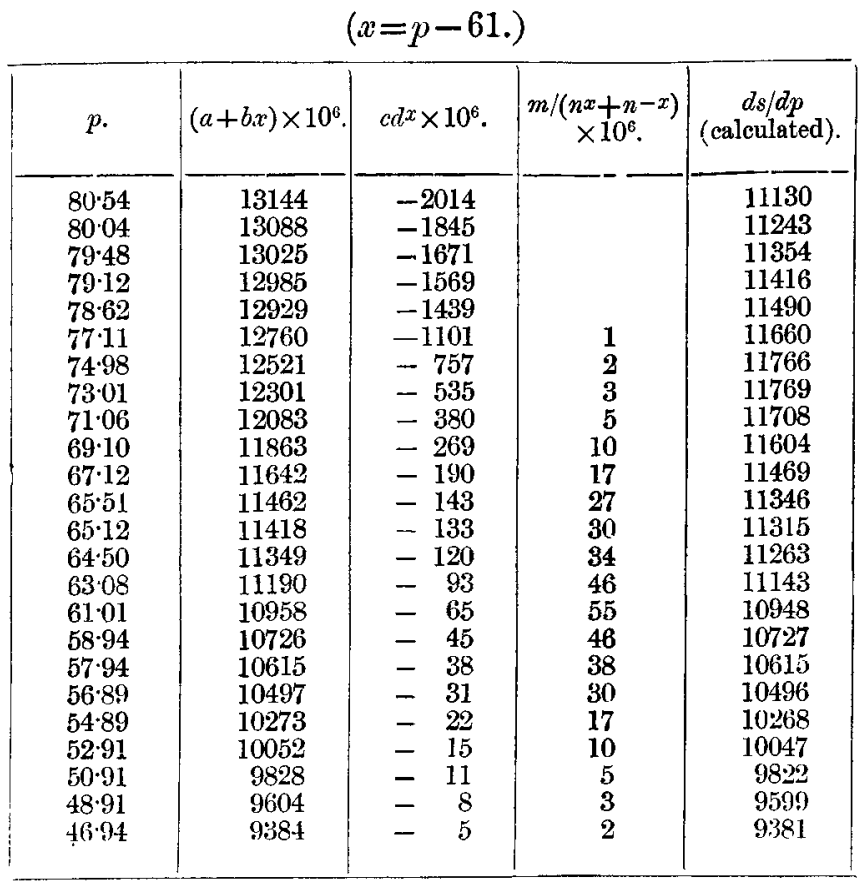

Before comparing these numbers with Mr. Pickering's experimental results it is convenient to deduce from his Table II. the values of $d s / d p$ given by his own smoothed curve. This can be done with fair accuracy for the greater number of points.

The following Table proves that for a large part of the curve the "second differential" at any point is to within 5 
in the last place the arithmetical mean of the corresponding quantities given for two other points of which the abscissæ $(p)$ differ by equal amounts from that of the point in question.

Thus the value of $d^{2} s / d p^{2}$ at 80.5 per cent. is the mean of the values at 81.5 per cent. and 79.5 per cent.

TABLE II.

\begin{tabular}{|c|c|c|c|c|c|}
\hline$p$ & $\frac{d^{2} s}{d p^{2}} \times 10^{6}$ & Mean. & $\mu$ & $\frac{d^{2} s}{d p^{2}} \times 10^{1 \mathrm{i}}$ & Mean. \\
\hline $81 \cdot 5$ & -370 & & 61.0 & 102 & 99 \\
\hline 80.5 & -290 & -290 & $59 \cdot 5$ & 105 & $102^{*}$ \\
\hline $79 \cdot 5$ & -210 & -215 & $58 \cdot 5$ & 102 & 105 \\
\hline 78.5 & -140 & -135 & $57 \cdot 5$ & 105 & 102 \\
\hline $77 \cdot 5$ & -60 & & $56 \cdot 5$ & 102 & 107 \\
\hline 76.5 & -80 & & 555 & 110 & 105 \\
\hline 755 & -50 & -45 & $54 \div 5$ & 108 & 111 \\
\hline $74 \div 5$ & -10 & & $53 \cdot 5$ & 112 & 109 \\
\hline $73 \cdot 5$ & -10 & & $52 \div 5$ & 110 & \\
\hline $72 \cdot 5$ & +2 & & $51 \cdot 5$ & & \\
\hline $71 \cdot 0$ & 53 & & 505 & & \\
\hline 69.0 & 61 & 62 & 490 & 111 & \\
\hline $67 \cdot 0$ & 72 & 70 & $47 \cdot 0$ & 105 & 104 \\
\hline 650 & 80 & 83 & $45 \cdot 0$ & 98 & 96 \\
\hline $63 \cdot 0$ & 94 & 91 & 430 & 88 & \\
\hline
\end{tabular}

* The difference of the two values of $d s / d p$, from which this number is obtained, is 127. I am not sture whether this discrepancy is due to a mistake or to the supposed existence of a point of discontinuity.

The intervals from which these mean values are calculated are at least twice as great as those which bave to be used in deducing values of $d s / d p$ at points intermediate to those given. Hence the errors introduced are not likely to exceed 2 or 3 in the last place.

I have therefore deduced from the numbers in Mr. Pickering's Table II. the readings on his curves at the points corresponding to his experiments.

In the following Table III., $p_{0}$ and $\left(\frac{d s}{d p}\right)_{0}$ are the values of these quantities given in Mr. Pickering's Table III. The percentage at the experimental points is $p$, and $p_{m}=\left(p+p_{0}\right) / 2$.

The second differential at $p_{m}$ is calculated from my Table II. above and indicated by $\left(\frac{d^{2} s}{d p^{2}}\right)$, and by means of this the value of $\frac{d s}{d p}$ at $p$ is deduced.

Thus, to give an example. If the values of $\frac{d^{2} s}{d p^{2}}$ at 80.5 per 
cent. and 79.5 per cent. are -290 and -210 respectively, at $80 \cdot 27$ per cent.

$$
\begin{aligned}
& \quad\left(\frac{d^{2} s}{d p^{2}}\right)_{m}=-210-80 \times 0.77=-272 . \\
& \therefore \quad \text { Since at } 80 \text { per cent. }\left(\frac{d s}{d p}\right)_{0}=11230, \\
& \quad \text { at } 80.54 \text { per cent. }\left(\frac{d s}{d p}\right)=11230-272 \times 0.54 \\
& =11230-147=11083 .
\end{aligned}
$$

\begin{tabular}{|c|c|c|c|c|c|}
\hline$p_{p}$ & $\left(\begin{array}{l}d s \\
d p\end{array}\right)_{0}$ & $p_{m}$ & $\left(\frac{d^{2} s}{d p^{2}}\right)_{m}$ & $p$ & $\frac{d s}{d p}$ \\
\hline $\begin{array}{l}80 \\
\ddot{7} 9 \\
\ddot{7} 8 \\
70 \\
68 \\
66 \\
64 \\
\ddot{ } \\
6 \% \\
60 \\
58 \\
57 \\
56 \\
54 \\
52 \\
48 \\
46\end{array}$ & $\begin{array}{c}115880 \\
11645 \\
11523 \\
11380 \\
11220 \\
" \\
11033 \\
10830 \\
10602 \\
10497 \\
10395 \\
10177 \\
9955 \\
9503 \\
9293\end{array}$ & $\begin{array}{l}80 \cdot 27 \\
80 \cdot 02 \\
79 \cdot 24 \\
79 \cdot 06 \\
78 \cdot 31 \\
70 \cdot 53 \\
68 \cdot 55 \\
66 \cdot 56 \\
64 \cdot 75 \\
64 \cdot 56 \\
64 \cdot 25 \\
62 \cdot 54 \\
60 \cdot 50 \\
58 \cdot 47 \\
57 \cdot 47 \\
56 \cdot 44 \\
54 \cdot 44 \\
52 \cdot 45 \\
48 \cdot 45 \\
46 \cdot 47\end{array}$ & $\begin{array}{r}-272 \\
-252 \\
-191 \\
-179 \\
-125 \\
+\quad 55 \\
63 \\
74 \\
82 \\
83 \\
85 \\
96 \\
103 \\
102 \\
105 \\
102 \\
108 \\
110 \\
109 \\
103\end{array}$ & $\begin{array}{l}80 \cdot 54 \\
80 \cdot 04 \\
79 \cdot 48 \\
79 \cdot 12 \\
78 \cdot 62 \\
71 \cdot 06 \\
69 \cdot 10 \\
67 \cdot 12 \\
65 \cdot 51 \\
65 \cdot 12 \\
64 \cdot 50 \\
63 \cdot 08 \\
61 \cdot 01 \\
58 \cdot 94 \\
57 \cdot 94 \\
56 \cdot 89 \\
54 \cdot 89 \\
52 \cdot 91 \\
48 \cdot 91 \\
46 \cdot 94\end{array}$ & $\begin{array}{r}11083 \\
11220 \\
11349 \\
11419 \\
11503 \\
11703 \\
11540 \\
11463 \\
11343 \\
11313 \\
11262 \\
11137 \\
10934 \\
10698 \\
10596 \\
10488 \\
10273 \\
10055 \\
9602 \\
9390\end{array}$ \\
\hline
\end{tabular}

TABLE III.

It remains to compare the two sete of values given by my single curve and Mr. Pickering's five curves respectively with his experimental numbers.

In doing so we must remember what tho estimated experimental error is. Mr. Pickering regards the possible error in the determination of a density as $=0 \cdot 000008=\epsilon$ say. Hence the possible error of $d s / d p$ is $2 \epsilon / \delta$, where $\delta$ is the difference between the percentages of the two points from which it is determined. In general $\delta=2$, so that the error of $d s / d p$ is \pm 0.000008 . The experiments at $18^{\circ}$ (which are alone treated of in this paper) are supposed to be less accurate than the others, but Mr. Pickering does not think that the error of experiment reaches twice the above value ${ }^{*}$. He admits that the

* It must, however, be remembered that the $18^{\circ}$ curve was chosen as the abnormal errors appear to be fewer and less than in other cases. 
curves prove that errors do exist of larger amounts than these, especially where the two points used in calculating $d s / d p$ were found from different solutions. I think, therefore, that I shall be expressing his views if I say that he regards the normal limit of error in the present set of experiments as $<16 \times 10^{-6}$ and $>8 \times 10^{-6}$, when the interval between the points used in finding $d s / d p$ is 2 per cent. The estimated maximum error calculated on this basis is shown in the following Table:-

TABLE IV.

\begin{tabular}{|c|c|c|c|c|c|c|c|}
\hline \multirow{3}{*}{$p$} & \multicolumn{2}{|c|}{$\frac{d s}{d p} \times 10^{4}$} & \multirow{3}{*}{$\begin{array}{c}\text { Deduced } \\
\text { from } \\
\text { Pickering's } \\
\text { numbers. } \\
\gamma .\end{array}$} & \multirow{3}{*}{$\beta-\alpha}$. & \multirow{3}{*}{$\gamma-\alpha$} & \multirow{2}{*}{\multicolumn{2}{|c|}{$\begin{array}{l}\text { Maximum error } \\
\text { estimated } \\
\text { numerically }\end{array}$}} \\
\hline & & Ca'culated & & & & & \\
\hline & $\begin{array}{c}\text { Observed. } \\
\boldsymbol{a} .\end{array}$ & $\begin{array}{l}\text { from } \\
\text { formula. } \\
\beta, .\end{array}$ & & & & less than & $\begin{array}{c}\text { greater } \\
\text { than }\end{array}$ \\
\hline 80.54 & 11117 & 11130 & 11083 & +13 & -34 & 30 & 15) \\
\hline $80 \cdot 0 \pm$ & 11251 & 11243 & 11220 & -8 & -31 & 15 & 8 \\
\hline $79 \cdot 48$ & 11400 & 11354 & 11349 & $-\cdots+6$ & -51 & 32 & 16 \\
\hline $79 \cdot 12$ & 11412 & $11+16$ & $11+19$ & -4 & +7 & 19 & 10 \\
\hline $78 \cdot 62$ & 11426 & 11490 & 11503 & +64 & 77 & 43 & 22 \\
\hline $77 \cdot 11$ & 11673 & 11660 & ....... & -13 & $\ldots$ & $1 \pm$ & 7 \\
\hline 7498 & 11753 & 11766 & ........ & +13 & & 16 & 8 \\
\hline 73.01 & 11767 & 11769 & ...... & +2 & $\ldots$ & 16 & 8 \\
\hline $71 \cdot 06$ & 11708 & 11708 & 11703 & 0 & -5 & 15 & 8 \\
\hline $69 \cdot 10$ & 11595 & 11604 & 11592 & +9 & -3 & 16 & 8 \\
\hline $67 \cdot 12$ & $11+67$ & 11469 & 11463 & +2 & -4 & 16 & 8 \\
\hline 65.51 & 11311 & 11346 & 11343 & +35 & +33 & 26 & 13 \\
\hline $65 \cdot 12$ & 11320 & 11315 & 11313 & -5 & -7 & 16 & 8 \\
\hline $64: 50$ & 11335 & 11263 & 11262 & -72 & -73 & 41 & 20 \\
\hline 63.08 & 11127 & 11143 & 11137 & +16 & +10 & 15 & 8 \\
\hline 61.01 & 10936 & 10948 & 10934 & +12 & -2 & 15 & 8 \\
\hline 58.94 & 10731 & 10727 & 10698 & -4 & $-33 *$ & 15 & 8 \\
\hline $57 \cdot 94$ & $1060^{\prime 2}$ & 10615 & 10596 & +13 & -6 & 7 & 4 \\
\hline 5689 & 10466 & 10496 & 10488 & +30 & +22 & 16 & 8 \\
\hline $54 \cdot 89$ & 10275 & 10268 & 10273 & -7 & -2 & 16 & 8 \\
\hline 52.91 & 10054 & $100 \pm 7$ & 10055 & -7 & $+\overline{1}$ & 16 & 8 \\
\hline 50.91 & $9811^{\dagger}$ & 9822 & & +11 & & 16 & 8 \\
\hline $48 \cdot 91$ & 9599 . & 9599 & 9602 & & +3 & 16 & 8 \\
\hline 46.94 & 9382 & 9381 & 9390 & -1 & +8 & 16 & 8 \\
\hline
\end{tabular}

* This error may be due to the uncertainty as to the value of $\frac{d^{2} s}{d p^{2}}$ at this point.

† This is given in Mr. Pickering's Table I. as 982.

In studying this Table one fact must be borne in mind. The last figure in all the columns is doubtful. In order to 
obtain it I have had to carry Mr. Pickering's own calculation of the value of $d s / d p$ from bis experiments to a place beyond that at which he-very properly in my opinion-stopped.

In the third column $(\beta)$ the last figure is affected -in the case of the higher percentages-by the third decimal in the percentages, which I have ignored. The error thus committed is, however, small.

As regards the fourth column $(\gamma)$, small errors may be introduced into the last place by the method of calculation.

If, then, we discard the last place and express each value of $\beta-\alpha$ and $\gamma-\alpha$ in terms of the number of units in the last place but one to which it most nearly approximates, we get the following Table, in which, for brevity, the values of $p$ and signs are omitted :-

TABLE V.

\begin{tabular}{|c|c||c|c||c|c|}
\hline$\beta-\alpha$ & $\gamma-\alpha$ & $\beta-\alpha$. & $\gamma-\alpha$ & $\beta-\alpha$. & $\gamma-\alpha$ \\
\hline 1 & 3 & 0 & 0 & 0 & $(?)$ \\
1 & 3 & 1 & 0 & 1 & 1 \\
$5 *$ & 5 & 0 & 0 & $3 *$ & 2 \\
0 & 1 & $3 *$ & 3 & 1 & 0 \\
$6^{*}$ & 8 & 0 & 1 & 1 & 0 \\
1 & & $7 *$ & 7 & 1 & 0 \\
1 & & 2 & 1 & 0 & 0 \\
0 & & 1 & 0 & 0 & 1 \\
\hline
\end{tabular}

It is evident from this Table that, taking a broad view of the relative claims of one continuous or five discontinuous curves to represent the results, there is not much to choose between them.

There are five points (marked with asterisks) at which both systems indicate large errors. These are partly accounted for by the fact that at most of them the differences between the values of $p$ by means of which $d s / d p$ was calculated were unusually small. At all of them also the two points required were obtained by means of different solutions, so that sources of error not included in Mr. Pickering's estimate of the maximum affected the results.

These points Mr. Pickering regards as abnormal. I will therefore neglect them, only remarking that if sources of error of such magnitude are introduced by a change in the fundamental solution from which the mixtures are made up, similar unreckoned errors may be introduced in the process of forming the individual mixtures. An inspection of the curves at $8^{\circ}, 28^{\circ}$, and $30^{\circ}$ confrms this suspicion. 
Omitting these points, however, the next most striking fact is that the values of $\gamma-\alpha$ are large for the two largest percentages, viz. 80.54 per cent. and 80.04 per cent. This is not a mistake. The value of $\frac{d s}{d p} \times 10^{6}$ at 80 per cent. is given in Mr. Pickering's Table III. as 11230, and the numerical value of $d s / d p$ diminishes as $p$ increases. The observed value at 80.04 per cent., 11251 , must therefore necessarily be a great deal too large.

If, then, we omit the abnormal points (marked with asterisks) and confine ourselves to those for which I have been able to calculate $\gamma-\alpha$, we find that, out of 14 points, errors of appreciable magnitude (to this order of approximation) occur eight times when my curve is used and seven times when Mr. Pickering's five curves are employed; the sum of the errors in the first case is 9 and in the second 11.

For my own part I think this result is sufficient to show that, in attempting to discriminate between representations of the experiments under consideration, Mr. Pickering is dealing with quantities less than the error of experiment.

The same conclusion is supported by a study of Table IV., if we admit that figures in the last place are trustworthy.

It is evident that my own results in the column $\beta-\alpha$ could be a little improved. Positive errors are the more numerous, and to make positive and negative errors balance we should have to subtract 2 from all the figures in that column. Hence it would have been better to choose for the constant $a$ the value 0.010955 instead of 0.010957 . I have not thought it worth while to rewrite the Tables to introduce this small correction.

The only point that I can see in Mr. Pickering's favour is that, if we omit the points at $80^{\circ} 54$ per cent. and $80^{\circ} 04$ per cent., and if we omit the points which I have called abnormal at which the errors are large, the errors obtained from his curves are kept more nearly within the limit 0.000008 than in the case of those obtained by myself.

I do not press the point that the maximum error in this case is admittedly larger than 0.000008 , but I must insist that it is extremely unlikely that errors so large as those at the abnormal points exist, and that there are none larger than the estimated amount elsewhere.

Why, for instance, are we to admit an error of 22 , or three times the lower limit to the maximum error, at 56.89 per cent., and insist that an error of 16 , which is only twice the same limit, is impossible at 63.08 per cent.? If we do make this extremely improbable assumption, it is of course possible to reduce the errors thus arbitrarily picked out by making the curve discontinuous. 
Thus, if between 53 and 58 we suppose the terms

$$
\{12-5(p-53)\} \times 10^{-6}
$$

to be added to the equation, the calculated values from 53 to 58 become

$$
10059,10270,10488 \text {, and 10602, }
$$

which make the values of $\beta-\alpha$

$$
5,-5,+22, \text { and } 0 \text {. }
$$

These are about of the same magnitude as the corresponding values of $\gamma-\alpha$, and, except at the abnormal * point, are less than 0.000008 .

Why the large difference matters so little and the small differences are so important $I$ do not know, but it appears to me that Mr. Pickering has been performing with a ruler an operation analogous to that I bave here performed by modifying a formula.

It is, however, possible to perform the same operation over other ranges. Thus, taking the percentages in round numbers, and subtracting from the part of the curve between 65 and 54 terms given by

we get the numbers in the following Table :-

$$
\left\{1+2 \cdot 6(60-p)^{2}\right\} \times 10^{-6}
$$

\begin{tabular}{|c|c|c|c|}
\hline$p$. & $\begin{array}{c}\text { Correction } \\
\text { term. }\end{array}$ & $\frac{d s}{d p}$. & $\beta-\alpha$. \\
\hline 63 & -24 & 11119 & -8 \\
61 & -4 & 10944 & +8 \\
59 & -4 & 10723 & -8 \\
58 & -11 & 10604 & +2 \\
57 & -24 & 10472 & +6 \\
\hline
\end{tabular}

The tenths of a per cent. omitted might affect the last figures to the extent of one unit; but the Table proves that it is possible by such devices to bring even the point at 56.89 per cent. into line with those near to it to within limits which are admittedly less than the error of experiment. A group of points from 64 to 74 per cent. shows errors no larger than Mr. Pickering's from 59 to 71 per cent. Such a method of treating the results, whether the instrument be a ruler or a formula, appears to me unjustifiable.

There is no doubt that the larger differences between obser-

* It must be remembered that Mr. Pickering does not apply this term to these points, though he appears to regard them as exceptional. 
vation and calculation are really due to errors. They occur in two instances, at all events, in pairs having opposite signs. One of these is near 79 per cent., the other near 65 per cent. They are precisely what might be expected if from any cause one density was more than usually erroneons. Is it not likely that other minor errors are to be explained in a similar way?

Mr. Pickering appears to me to be on the horns of a dilemma. If we assume the larger values of the maximum error to be correct, then the values of $\beta-\alpha$ are for the most part (except at the abnormal points) so well within the limits of the error of experiment that the whole discussion resolves itself (even from his point of view) into a controversy about matters less than the error of experiment. If the lower limit is adopted, then he must explain why, when at 64.50 per cent. the value of $\gamma-\alpha$ is some three and a half times greater than the estimated maximuin error, the theory of discontinuity is required to acconnt for the much smaller discrepancies found elsowhere.

Horizontal lines are drawn in Table IV. at the points where Mr. Pickering believes that there are breaks in the continuity of the curve. The differences $\beta-\alpha$ show no sign of regularity in these intervals, they are for the most part of the same order of magnitude as the estimated error of experiment ; and any argument which could be drawn from the fact that they exceed the lower ralues which may be assigned to it is nentralized by the fact that in some cases they unquestionably exceed the largest limits Mr. Pickering bas specifically mentioned. Finally, to obtain the last place it has been necessary to strain the calculations, and to carry them in some instances to a place further than Mr. Pickering himself has done. If therefore we adopt the safer course of neglecting figures $<10^{-3}$, the continuous equation expresses the facts at least as well as the five discontinuous curves.

It is of course logically open to Mr. Pickering to claim that his case is not disproved until a process similar to that which I have adopted has been successfully applied in a much larger number of instances, So far as I am concerned I can only reply that $I$ think my result places him in the position of having to prove a negative, and that I certainly cannot undertake to devote myself to the multiplication of such evidence.

I have before stated that I think that the curves in some parts-if not discontinuous-have peculiar features which suggest special physical causes. Thus between 84 and 94 per cent. they are obviously nearly straight lines. My doubts have always had reference to the minor changes of curvature and to the use of the ruler in detecting them. They are confirmed by the above investigation.

Phil. Mag. S. 5. Vol. 32. No.196. Sept. 1891. 